\title{
PREDICTION OF SHEAR CAPACITY OF UHPC-CONCRETE COMPOSITE STRUCTURAL MEMBERS BASED ON EXISTING CODES
}

\author{
Hor YIN $^{1}\left(\mathbb{D}\right.$, Kazutaka SHIRAI ${ }^{*} \mathbb{D}$, Wee TEO $^{3}$ \\ ${ }^{1}$ Graduate School of Engineering, Hokkaido University, Sapporo, Japan \\ ${ }^{2}$ Faculty of Engineering, Hokkaido University, Sapporo, Japan \\ ${ }^{3}$ School of Energy, Geoscience, Infrastructure and Society, Heriot Watt University Malaysia, Putrajaya, Malaysia
}

Received 25 May 2018; accepted 10 September 2018

\begin{abstract}
Reinforced concrete (RC) structural members strengthened with ultrahigh-performance concrete (UHPC) have shown excellent performance in past experimental investigations. However, methods of predicting their capacity are currently very limited. This paper presents six independent methods of predicting the shear capacity of UHPC-concrete composite members based on the application of existing design codes. Three of these methods are based on the conversion of the volume fraction of steel fibres in the UHPC in an equivalent longitudinal steel ratio. The other three methods involve the computation of the shear strength as a sum of the contributions to the shear strength by the RC member and the UHPC layer, each of which is independently calculated. It was demonstrated that the proposed methods based on existing design codes are able to predict the strength of UHPC-concrete composite members with reasonable accuracy.
\end{abstract}

Keywords: ultrahigh-performance concrete, reinforced concrete, composite members, code prediction, shear strength, UHPC layer.

\section{Introduction}

Recently, ultrahigh-performance concrete (UHPC) has been increasingly considered as a potential tool in strengthening reinforced concrete $(\mathrm{RC})$ structural elements. Methods of using UHPC to strengthen parts of structures that fully exploit the outstanding properties of UHPC have been proposed by Brühwiler and Denarie (2008). They validated these methods using four full-scale applications. Their study has demonstrated that UHPC is excellently suited for use in either cast-in-situ or precast applications.

Over the last two decades, many experimental studies have been conducted on UHPC-concrete composite members (Brühwiler, Denarie 2008; Alaee, Karihaloo 2003; Habel et al. 2007; Noshiravani, Brühwiler 2013a, 2013b; Yin et al. 2017). The excellent properties of UHPC in terms of strain hardening and energy absorption (Graybeal, Baby 2013; Habel 2004; Yoo, Banthia 2016; Graybeal 2005; Yoo, Yoon 2016; Wille et al. 2014) lead to members showing significantly improved structural performance after being strengthened with a UHPC layer. In addition, UHPC has been applied to the strengthening of RC members in the form of precast plates (Alaee, Karihaloo 2003), overlays (Habel et al. 2007; Noshiravani, Brühwiler 2013b;
Oesterlee 2010), and patch material for rehabilitation (Yin et al. 2017). UHPC has been shown to greatly influence the overall response of structural members, including their cracking development patterns, ultimate strength, and ductility.

However, studies on analytical methods for the shear strength prediction of composite structural members have been very limited. Noshiravani and Brühwiler (2013a) have reported an analytical model for the flexural-shear resistance of composite beams. They adopted an elasticplastic fictitious composite hinge model for the cracking in RC members and considered the interaction between the two elements of the composite members; however, this method requires several analytical steps.

For non-composite members, the structural capacity can be obtained using existing design codes. Several current design codes for RC structural members, such as ACI 318 (2008), or for fibre-reinforced concrete (FRC) members, such as ACI 544 (1988), involve the calculation of the shear strength as the sum of the shear force resisted by normal-strength concrete (NSC) or UHPC and by shear reinforcement.

*Corresponding author. E-mail: shirai.kazutaka@eng.hokudai.ac.jp 
To date, no design provisions have been made available for the prediction of the shear capacity of UHPC-concrete composite members. Methods that can be used to predict the shear capacity are therefore needed. Applications based on the modification of existing design models of RC or FRC structures could be useful because they are simple and easy to use.

For this purpose, this paper introduces six methods of predicting the shear capacity of UHPC-concrete composite members based on modifications to existing design models. Nine UHPC-concrete composite slabs tested by Yin et al. (2017) were used to verify the proposed methods. The remainder of this paper is organized as follows. A brief description of the current design models for noncomposite members is provided. The six methods are then described in detail, and the predicted shear capacities are verified against test results. Moreover, the predicted failure mode derived from the calculated flexural moment reported by Shirai et al. (2018) is discussed. In addition, the present paper expands on a previous study (Yin et al. 2018) by adding new methods, results, and findings.

\section{Description of specimens and test results}

\subsection{Geometric details of specimens}

This section gives the parameters of RC slabs strengthened with various UHPC configurations that were previously tested by Yin et al. (2017) and summarises the test results, which were used to validate the analytical methods in the present study. The different UHPC thicknesses and the presence or absence of the additional steel rebar in UHPC layer of the slab specimens as seen in Figure 1 could allow to assess the influence of the suitability of the methods for calculating the shear capacity. The full details of the previous experiment can be found in the original document (Yin et al. 2017).
Nine slabs of $1600 \mathrm{~mm}$ in length with the clear span of $1200 \mathrm{~mm}$ were tested in the previous study. The non-composite specimens (RE-0 and RE-100) had a shear span-toeffective depth $(a / d)$ ratio of 8.11. Of nine specimens, five were classified into the RE series, which had UHPC patches of different thicknesses applied in the tension zone for the repair and rehabilitation of the structural members. All slabs in the RE series had five high-tensile-strength rebars of $12 \mathrm{~mm}$ in diameter at the top and bottom, as shown in Figure 1. The other four slabs were classified as the OV series and had similar cross-sectional dimensions as RE series but with two additional UHPC overlay patches strengthening the tension zone. There were two slab specimens for each considered overlay thickness: one was not reinforced, whereas the other had five high-tensilestrength rebars of $10 \mathrm{~mm}$ in diameter as longitudinal reinforcement. The geometric and reinforcement details of the experimental specimens are summarised in Table 1.

\subsection{Material properties}

The average mechanical properties of the NSC and UHPC are listed in Table 2. UHPC with a steel fibre volume fraction of $3 \%$ was adopted. Straight steel fibres of $13 \mathrm{~mm}$ in length and $0.2 \mathrm{~mm}$ in diameter were used. The detailed UHPC mix design and the procedures for the preparation of the slabs can be found in the original document (Yin et al. 2017). The longitudinal reinforcement properties are given in Table 1.

\subsection{Summary of test results}

Figure 2 shows typical crack patterns of the RE and OV series after testing. The specimens in the RE and OV series mainly failed in flexure and shear, respectively. The debonding of the UHPC from the RC members induced by shear cracks was also observed in the OV series. For

Table 1. Details of the specimens (Yin et al. 2017)

\begin{tabular}{|c|c|c|c|c|c|c|c|c|c|c|}
\hline \multirow{3}{*}{ Specimen } & \multicolumn{3}{|c|}{ Geometric } & \multicolumn{7}{|c|}{ Longitudinal reinforcement } \\
\hline & \multirow{2}{*}{$\begin{array}{c}b \\
(\mathrm{~mm})\end{array}$} & \multirow{2}{*}{$\begin{array}{c}h \\
(\mathrm{~mm})\end{array}$} & \multirow{2}{*}{$\begin{array}{c}h_{U} \\
(\mathrm{~mm})\end{array}$} & \multirow[b]{2}{*}{$\begin{array}{c}A_{s}^{\prime} \\
\left(\mathrm{mm}^{2}\right)\end{array}$} & \multirow{2}{*}{$\begin{array}{c}A_{s} \\
\left(\mathrm{~mm}^{2}\right)\end{array}$} & \multirow{2}{*}{$\begin{array}{c}A_{s U} \\
\left(\mathrm{~mm}^{2}\right)\end{array}$} & \multicolumn{2}{|c|}{ T12 } & \multicolumn{2}{|c|}{ T10 } \\
\hline & & & & & & & $\begin{array}{c}f_{y} \\
(\mathrm{MPa})\end{array}$ & $\begin{array}{c}f_{\max } \\
(\mathrm{MPa})\end{array}$ & $\begin{array}{c}f_{y} \\
(\mathrm{MPa})\end{array}$ & $\begin{array}{c}f_{\max } \\
(\mathrm{MPa})\end{array}$ \\
\hline RE-0 & 300 & 100 & - & 565 & 565 & - & 501.6 & 564.7 & - & - \\
\hline RE-20 & 300 & 100 & 20 & 565 & 565 & - & 501.6 & 564.7 & - & - \\
\hline RE-32 & 300 & 100 & 32 & 565 & - & 565 & 501.6 & 564.7 & - & - \\
\hline RE-50 & 300 & 100 & 50 & 565 & - & 565 & 501.6 & 564.7 & - & - \\
\hline RE-100 & 300 & 100 & 100 & 565 & - & 565 & 501.6 & 564.7 & - & - \\
\hline OV-25 & 300 & 125 & 25 & 565 & 565 & - & 501.6 & 564.7 & - & - \\
\hline OV-25a & 300 & 125 & 25 & 565 & 565 & 393 & 501.6 & 564.7 & 474.9 & 506.6 \\
\hline OV-50 & 300 & 150 & 50 & 565 & 565 & - & 501.6 & 564.7 & - & - \\
\hline OV-50a & 300 & 150 & 50 & 565 & 565 & 393 & 501.6 & 564.7 & 474.9 & 506.6 \\
\hline
\end{tabular}

Note: $b$ - width of the specimen; $h$ - height of the specimen; $h_{U}$ - thickness of the UHPC layer; $A_{s}^{\prime}$ - area of the top longitudinal reinforcement; $A_{s}$ - area of the bottom longitudinal reinforcement; $A_{s U}$ - area of the longitudinal reinforcement provided in the UHPC layer; $f_{y}$ - yield strength of the longitudinal reinforcement; $f_{\max }$ - maximum strength of the longitudinal reinforcement. 


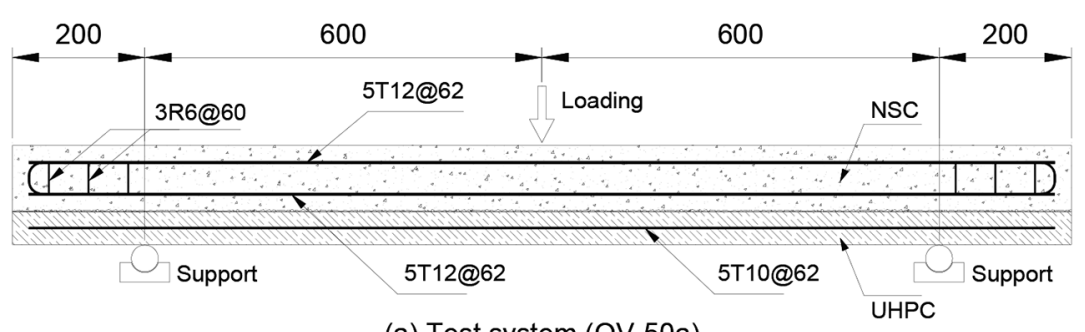

(a) Test system (OV-50a)
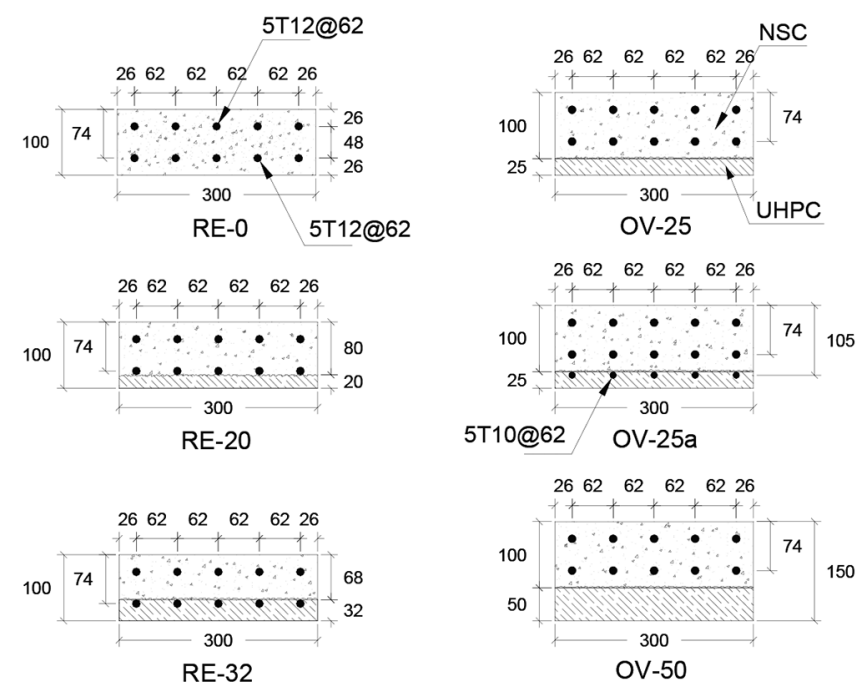

OV-50
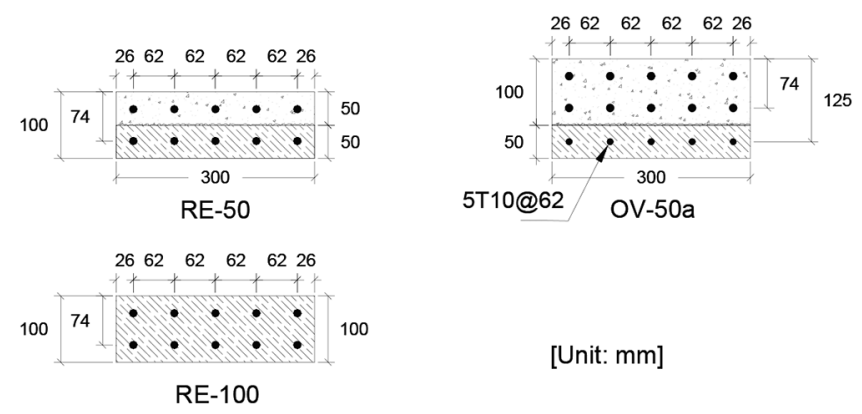

(b) RE series specimens

[Unit: $\mathrm{mm}$ ]

(c) OV series specimens

Figure 1. Test system and specimen details (Yin et al. 2017)

Table 2. Average mechanical properties of concrete (Yin et al. 2017)

\begin{tabular}{|l|c|c|c|}
\hline Material & $\begin{array}{c}\text { Compressive } \\
\text { strength } \\
(\mathrm{MPa})\end{array}$ & $\begin{array}{c}\text { Flexural } \\
\text { strength } \\
(\mathrm{MPa})\end{array}$ & $\begin{array}{c}\text { Young's } \\
\text { modulus } \\
(\mathrm{GPa})\end{array}$ \\
\hline NSC & 23 & - & $22.5^{\S}$ \\
\hline UHPC & 153 & 27.4 & $58.1^{\S}$ \\
\hline
\end{tabular}

Note: ${ }^{\S}$ Calculated using $E_{c}=4700\left(f_{c}^{\prime}\right)^{0.5}$ where $f_{c}^{\prime}$ is the compressive strength in megapascals (ACI 318 2008).

non-composite RC members, the shear behaviour and failure modes depend on the a/d ratio. According to Kotsovos (1983) and Kani (1964), the causes of the diagonal shear failure are associated with the force transmission between longitudinal rebar and concrete. With the use of high steel ratio $(=2.5 \%)$ of the specimens adopted in the present study, the force transmitted to concrete led to a significant reduction of the load sufficient to cause diagonal shear cracks.

Figure 3(a) and (b) illustrates the load-deflection curves of the specimens of the RE and OV series, respectively. As shown in Figure 3(a), all rehabilitated slabs (RE-20, RE-32, and RE-50) experienced extensive deflection hardening and ductility during the post-cracking stage. Although no improvement to the ultimate load was found in any of the rehabilitated slabs in comparison with RE-0 (Figure 3(a)), it was reached at a larger displacement as a result of the excellent energy absorption capabilities of the rehabilitated slabs (Yin et al. 2017).

For the OV series (Figure 3(b)), because of the strengthening effect, including the increase in the total specimen height, the RC members with a UHPC layer in the tension zone showed an enhanced overall response, including improved stiffness and load carrying capacity, in comparison with RE-0. Although the initial stiffness of the specimens 

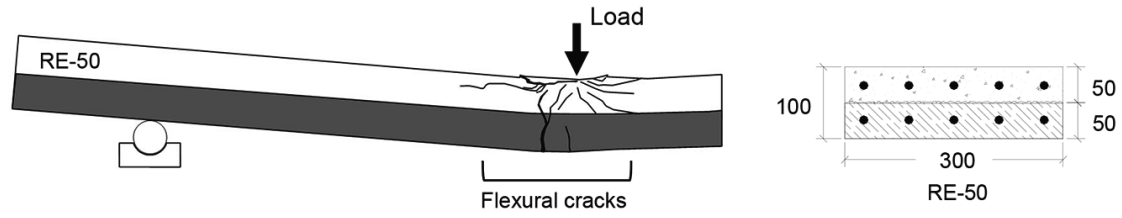

(a) Specimen RE-50
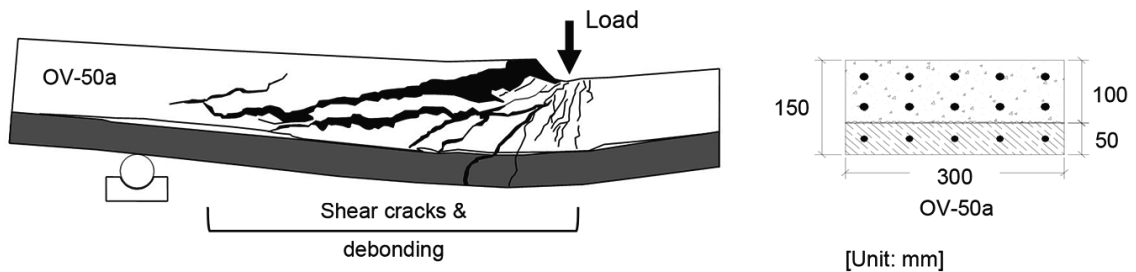

(b) Specimen OV-50a

[Unit: $\mathrm{mm}]$

Figure 2. Typical crack patterns observed for the specimens in the RE and OV series (Yin et al. 2017)

containing reinforcing bars in the UHPC did not seem to differ from that of the specimens without rebar, as demonstrated by the similarity in the behaviour of OV-50 and OV-50a, the reinforcing bars in the UHPC increased the ultimate load of the members relative to their non-reinforced counterparts (Yin et al. 2017).

\section{Review of existing design codes}

\subsection{Design shear strength models for RC members}

Current design provisions for non-composite RC members, including ACI 318 (2008), Eurocode 2 (EN 1992-1-1 2004) and JSCE-2007 (2010), adopt similar approaches for calculating the nominal shear capacity $V_{n}$ as a sum of the contributions of the transverse reinforcement, $V_{s}$, and the concrete, $V_{c}$, as follows:

$$
V_{n}=V_{s}+V_{c}
$$

For shear reinforcement (stirrups), $V_{s}$ is given as $V_{s}=A_{s w} f_{y t} d / s$, where $A_{s w}$ is the area of shear reinforcement, $f_{y t}$ is the yield strength of stirrups, $d$ is the effective depth, and $s$ is the spacing of the stirrups. For concrete, $V_{c}$ can be expressed as follows for the considered design codes:

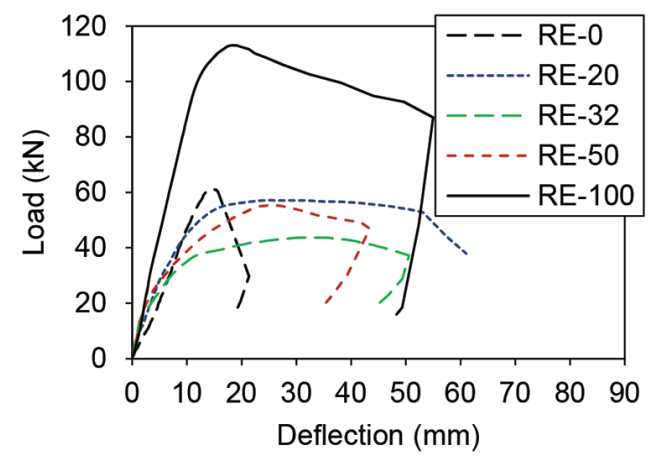

(a) RE series
- Design code ACI 318 (2008):

$$
V_{c}=\left(0.16 \lambda \sqrt{f_{c}^{\prime}}+17 \rho_{s} \frac{V_{u} d}{M_{u}}\right) b_{w} d,
$$

where $\lambda$ is the reduction factor, $f_{c}^{\prime}[\mathrm{MPa}]$ is the compressive strength of concrete, $\rho_{s}$ is the longitudinal ratio, $V_{u}$ is the shear force, $M_{u}$ is the ultimate moment, $d$ is the effective depth, and $b_{w}$ is the web width.

- Design code EC2:

$$
V_{c}=\left\{\frac{0.18}{\gamma_{c}} k\left[100 \rho_{s} f_{c k}\right]^{\frac{1}{3}}\right\} b_{w} d,
$$

where $\gamma_{c}$ is the concrete safety factor, $\rho_{s}$ is the longitudinal ratio, $f_{c k}[\mathrm{MPa}]$ is the concrete strength, $d$ is the effective depth, $b_{w}$ is the web width, and $k$ is the size effect factor. Here, $k$ is given by:

$$
k=1+\sqrt{\frac{200}{d}} \leq 2.0 \quad(d \text { in } \mathrm{mm}) .
$$

- Design guideline JSCE-2007 (2010):

$$
V_{c}=\frac{\beta_{d} \beta_{p} \beta_{n} f_{v c d} b_{w} d}{\gamma_{b}} .
$$

Figure 3. Load-deflection curves of the test specimens (Yin et al. 2017) 
Here:

$$
\begin{array}{ll}
f_{v c d}=0.2 \sqrt[3]{f_{c d}^{\prime}}\left(f_{c d}^{\prime} \text { in } \mathrm{MPa}\right), & \text { where } f_{v c d} \leq 0.72 \mathrm{MPa} ; \\
\beta_{d}=\sqrt[4]{\frac{1000}{d}}(d \text { in } \mathrm{mm}), & \text { where } \beta_{d} \leq 1.5 ; \\
\beta_{p}=\sqrt[3]{100 p_{v}}, & \text { where } \beta_{p} \leq 1.5 ; \\
\beta_{n}=1+\frac{2 M_{0}}{M_{u d}}\left(N_{d}^{\prime} \geq 0\right), & \text { where } \beta_{n} \leq 2 ; \\
\beta_{n}=1+\frac{4 M_{0}}{M_{u d}}\left(N_{d}^{\prime}<0\right), & \text { where } \beta_{n} \geq 0 .
\end{array}
$$

In these equations, $N_{d}^{\prime}$ is the design axial compressive force, $M_{u d}$ is the flexural capacity without consideration of the axial force, $M_{0}$ is the flexural moment necessary to cancel the stress due to the axial force at the extreme tension fibre, $b_{w}$ is the web width, $d$ is the effective depth, $p_{v}$ is the reinforcing bar ratio $\left(p_{v}=A_{s} /\left(b_{w} d\right)\right), A_{s}$ is the area of tension reinforcement, $f_{c d}^{\prime}$ is the design compressive strength of concrete, and $\gamma_{b}(=1.3)$ is the member factor.

\subsection{Design shear strength models for FRC members}

The current design guidelines for FRC members ACI 544 (1988), MC 2010 (2010) and JSCE (2006) (JSCE Concrete Committee 2006) can be summarised as follows.

- Design guideline ACI 544 (1988):

This design code gives the nominal shear strength $V_{n}$ for FRC members as

$$
V_{n}=\frac{2}{3} f_{c t}\left(\frac{d}{a}\right)^{0.25} b_{w} d,
$$

where $f_{c t}$ is the tensile strength of FRC, $a$ is the distance from the loading point to the support, $d$ is the effective depth, and $b_{w}$ is the web width. It is important to note that the empirical formula does not account for factors widely recognised as significantly influencing the shear strength, including the fibre length, fibre type, and the longitudinal rebar ratio.

- Design guideline MC 2010 (2010):

This code provides the shear strength for FRC members with or without shear reinforcement (stirrups). The nominal shear strength $V_{n}$ can be expressed as

$$
V_{n}=V_{c, F}+V_{s},
$$

where $V_{c, F}$ is the FRC contribution to the shear strength and $V_{s}$ is the shear strength provided by the stirrups.

In this code, the contribution of fibres to the shear capacity may be taken into account; however, it is recommended to use this code only when the FRC exhibits hardening tensile behaviour. Instead of separately predicting the fibrous contribution, the FRC shear contribution $V_{c, F}$ is estimated solely by modifying the formula for $\mathrm{RC}$ members (Eqn (3)) by adding an extra term, as

$$
V_{c, F}=\left\{\frac{0.18}{\gamma_{c}} k\left[100 \rho_{s}\left(1+7.5 \frac{f_{\text {Ftuk }}}{f_{c t k}}\right) f_{c k}\right]^{\frac{1}{3}}\right\} b_{w} d,
$$

where $\gamma_{c}$ is the safety factor, $\rho_{s}$ is the longitudinal ratio, $f_{\text {Ftuk }}$ is the characteristic value of the ultimate residual tensile strength for the FRC, $f_{c t k}$ is the characteristic value of the FRC tensile strength, $f_{c k}[\mathrm{MPa}]$ is the concrete strength, $d$ is the effective depth, $b_{w}$ is the web width, and $k$ is the size effect factor. Here, $k$ is given by

$$
k=1+\sqrt{\frac{200}{d}} \leq 2.0 \quad(d \text { in } \mathrm{mm}),
$$

and $V_{s}$ is given as

$$
V_{s}=\frac{A_{w}}{s} z f_{y w d}(\cot \phi+\cot \theta) \sin \phi .
$$

In these Eqns, $A_{w}$ is the cross-sectional area of the stirrups, $s$ is the spacing of stirrups, $f_{y w d}$ is the design yield strength of the stirrups, $\theta\left(=45^{\circ}\right)$ is the angle between the concrete compression strut and the beam axis perpendicular to the shear force, $\varphi$ is the angle between shear reinforcement and the beam axis perpendicular to the shear force, and $z$ is the inner lever arm and is recommended to be set to $z=0.9 d$.

- Design guideline JSCE (2006)

This recommendation considers the contributions of the cement matrix and the steel fibres to the shear strength of the ultrahigh-strength fibre-reinforced concrete members. According the recommendation, the nominal shear strength $V_{n}$ is given as

$$
V_{n}=V_{c}+V_{F}+V_{p e d} \text {, }
$$

where $V_{c}$ is the contribution of the cement matrix to the shear strength of a member that has no shear reinforcement (stirrups), $V_{F}$ is the contribution of the reinforced fibres, and $V_{p e d}$ is the component of effective tensile force of the longitudinal tendons.

$$
\begin{aligned}
& V_{c} \text { is calculated as } \\
& V_{c}=\frac{0.18 \sqrt{f_{c d}^{\prime}} b_{w} d}{\gamma_{b}},
\end{aligned}
$$

where $f_{c d}^{\prime}[\mathrm{MPa}]$ is the design compressive strength, $b_{w}$ is the web width, $d$ is the effective depth, and $\gamma_{b}(=1.3)$ is the member factor.

$$
\begin{aligned}
& V_{F} \text { is given by } \\
& V_{F}=\frac{\left(f_{v d} / \tan \beta_{u}\right) b_{w} z}{\gamma_{b}},
\end{aligned}
$$

where $f_{v d}$ is the design average tensile strength perpendicular to diagonal cracks, $\beta_{u}\left(>30^{\circ}\right)$ is the angle between the member axis and a diagonal crack, $z$ is the inner lever arm and is recommended to be set to $d / 1.15$, and $\gamma_{b}$ is the member factor that can be taken as 1.3.

In the recommendation, because of the fibre orientation included in the design models, $f_{v d}$ can be determined as 


$$
f_{v d}=\frac{1}{w_{\lim }} \int_{0}^{w} \frac{\sigma_{k}(w)}{\gamma_{c}} d w=\frac{1}{w_{\lim }} \int_{0}^{w} \sigma_{d}(w) d w
$$

where $w$ is the crack width, $w_{\text {lim }}$ is the limit value of the crack width and generally taken as $0.3, \sigma_{k}(w)$ and $\sigma_{d}(w)$ are tensile softening curves, and $\gamma_{c}(=1.3)$ is the material factor.

$$
\begin{aligned}
& V_{p e d} \text { in the recommendation is expressed as } \\
& V_{p e d}=\frac{P_{e d} \sin \alpha_{p}}{\gamma_{b}},
\end{aligned}
$$

where $P_{e d}$ is the effective tensile force of the tendons, $\alpha_{p}$ is the angle formed by the tendons and the member axis, and $\gamma_{b}(=1.1)$ is the member factor.

\section{Shear strength of UHPC-concrete composite members}

\subsection{Overview}

The methods of predicting the shear strength of UHPCconcrete composite members proposed in the present study is based on the existing design Eqns explained in Section 2 (ACI 318 2008, EN 1992-1-1 2004, JSCE-2007 2010, ACI 544 1988, MC 2010 2010, and JSCE 2006). In addition, Noshiravani and Brühwiler (2013b) and Yin et al. (2017) have reported that the predominant contributor to the shear strength of composite members is the web of the RC members. The results of their studies suggest that the shear contribution of thin UHPC layers may be relatively small. The shear capacity may depend on the tensile strength of the UHPC, which may be dominated by steel fibres, and/or the mechanical weak bond interface between the UHPC and the RC members.

For this purpose, six different methods were individually proposed to compute the nominal shear resistance of UHPC-concrete members. Three of them, named Methods $\mathrm{A} 1, \mathrm{~A} 2$, and $\mathrm{A} 3$, were based on converting the volume fraction of steel fibres to the equivalent longitudinal steel ratio. The remaining three methods, named Methods B1, $\mathrm{B} 2$, and B3, involve summing the two contributions $V_{c}$ and $V_{U H P C}$ to the shear resistance, where $V_{c}$ is the contribution of the RC members and $V_{U H P C}$ is the contribution of the UHPC layer. It should be mentioned that because the specimens used in this study had no shear reinforcement, the shear strength of the reinforcement was omitted. In addition, although Methods A1, A3, and B1 have been presented previously (Yin et al. 2018), prediction from other existing codes were investigated in this study to further demonstrate their accuracy.

\subsection{Methods of converting the volume fraction of steel fibres}

Methods A1, A2, and A3 for the UHPC-concrete composite members were based on the current design codes for RC members ACI 318 (2008), EN 1992-1-1 (2004), and JSCE-2007 (2010), respectively. The composite members were modelled as equivalent RC members by consider- ing the contribution of the steel fibres in the UHPC to the equivalent longitudinal rebar ratio. This approach was adopted because the contribution of the UHPC layer to the shear capacity of the composite members may depend on the tensile strength of the UHPC when the volume fraction of steel fibres is high (Noshiravani, Brühwiler 2013; Yin et al. 2017, 2018).

In the present study, the equivalent rebar ratio $\rho$ was given as:

$$
\rho=\rho_{s}+\rho_{\text {eq, }, F}
$$

where $\rho_{s}$ is the rebar ratio of the RC members and $\rho_{e q, F}$ is the equivalent ratio of the volume steel fibres. $\rho_{s}$ is given as:

$$
\rho_{s}=\frac{A_{s}}{b_{w} d},
$$

where $A_{s}$ is the area of the longitudinal rebar, $d$ is the effective depth, and $b_{w}$ is the width of the specimen sections. $\rho_{e q, F}$ is calculated as:

$$
\rho_{e q, F}=\% \text { Vol. }\left(\frac{f_{c t}}{f_{y}}\right)\left(\frac{A_{U H P C}}{A_{R C}}\right),
$$

where $f_{c t}$ is the tensile stress of UHPC and is taken as $f_{c t}=0.3\left(f_{c}^{\prime}\right)^{2 / 3}$ with $f_{c}^{\prime}[\mathrm{MPa}]$ the compressive strength of UHPC; $f_{y}$ is the yield strength of the longitudinal rebar; $A_{U H P C}\left(=b_{w} h_{U}\right)$ and $A_{R C}\left(=b_{w} d\right)$ are the areas of the UHPC and RC part, respectively; $b_{w}$ is the width; $h_{U}$ is the UHPC thickness; $d$ is the effective depth; and \%Vol. is the volume ratio of steel fibres. The effective depth $d$ was assumed to be:

$$
d=h_{c}+\frac{h_{U}}{2},
$$

where $h_{c}$ is the height of the RC members.

Therefore, the shear strength $V_{n, \text { compos }}$ of the UHPCconcrete composite members can be expressed as follows based on the considered design codes.

(a) Method A1: Based on ACI 318 (2008):

$$
V_{n, \text { compos }}=\left(0.16 \lambda \sqrt{f_{c}^{\prime}}+17\left(\rho_{s}+\rho_{e q, F}\right) \frac{V_{u} d}{M_{u}}\right) b_{w} d,(20)
$$

where $\lambda$ is the reduction factor, $f_{c}^{\prime}[\mathrm{MPa}]$ is the compressive strength of NSC, $V_{u}$ is the shear force, $M_{u}$ is the ultimate moment, $d$ is the effective depth, $b_{w}$ is the web width, $\rho_{s}$ is the longitudinal ratio, and $\rho_{e q, F}$ is the equivalent volume ratio of steel fibres (Eqn (18)).

(b) Method A2: Based on EN 1992-1-1 (2004):

$$
V_{n, \text { compos }}=\left\{\frac{0.18}{\gamma_{c}} k\left[100\left(\rho_{s}+\rho_{e q, F}\right) f_{c k}\right]^{\frac{1}{3}}\right\} b_{w} d \text {, }
$$

where $\gamma_{c}$ is the concrete safety factor, $k$ is the size effect factor, $b_{w}$ is the web width, $d$ is the effective depth, $f_{c k}$ $[\mathrm{MPa}]$ is the compressive strength of NSC, $\rho_{s}$ is the longitudinal ratio, and $\rho_{e q, F}$ is the equivalent volume ratio of steel fibres (Eqn (18)).

(c) Method A3: Based on JSCE-2007 (2010):

$V_{c}=\frac{\beta_{d} \beta_{p} \beta_{n} f_{v c d} b_{w} d}{\gamma_{b}}$. 
Here:

$$
\begin{array}{ll}
f_{v c d}=0.2 \sqrt[3]{f_{c d}^{\prime}}\left(f_{c d}^{\prime} \text { in } \mathrm{MPa}\right), \text { where } f_{v c d} \leq 0.72 \mathrm{MPa} ; \\
\beta_{d}=\sqrt[4]{\frac{1000}{d}}(d \text { in mm }), & \text { where } \beta_{d} \leq 1.5 ; \\
\beta_{p}=\sqrt[3]{100\left(p_{v}+\rho_{e q, F}\right)}, & \text { where } \beta_{p} \leq 1.5 ; \\
\beta_{n}=1+\frac{2 M_{0}}{M_{u d}} \quad\left(N_{d}^{\prime} \geq 0\right), & \text { where } \beta_{n} \leq 2 ; \\
\beta_{n}=1+\frac{4 M_{0}}{M_{u d}} \quad\left(N_{d}^{\prime}<0\right), & \text { where } \beta_{n} \geq 0 .
\end{array}
$$

In these Eqns, $\gamma_{b}(=1.3)$ is the member factor, $N_{d}^{\prime}$ is the design axial compressive force, $M_{u d}$ is the flexural capacity without consideration of the axial force; $M_{0}$ is the flexural moment necessary to counteract the stress due to the axial force at the extreme tension fibre, $f_{c d}^{\prime}$ is the design compressive strength of concrete, $b_{w}$ is the width, $d$ is the effective depth, $p_{v}\left(=A_{s} /\left(b_{w} d\right)\right)$ is the reinforcing bar ratio, $A_{s}$ is the area of tension reinforcement, and $\rho_{e q, F}$ is the equivalent ratio of the volume steel fibres (Eqn (18)).

\subsection{Methods based on summing the two shear contributions}

In Methods B1, B2, and B3, the shear contributions $V_{c}$ and $V_{U H P C}$ of the UHPC-concrete composite members are independently computed and summed. The RC contribution $V_{c}$ was obtained using the current design codes for RC members, ACI 318 (2008), EN 1992-1-1 (2004), and JSCE2007 (2010). For the UHPC contribution $V_{U H P C}$, the three design guidelines ACI 544 (1988), MC 2010 (2010), and JSCE (2006) were employed. The calculation was based on the assumption that the UHPC-concrete composite members can be considered as two independent parts (the NSC and UHPC components) that simultaneously fail at the same time. Although this assumption may not correspond to the shear patterns of the actual tests on UHPC in the composite members conducted by Yin et al. (2017), for the sake of simplicity and to allow comparison with the other methods, this assumption was adopted. The nominal shear strength $V_{n \text {,compos }}$ could then be given as follows based on the considered design codes.

(a) Method B1: Based on ACI 318 (2008) and ACI 544 (1988):

$$
V_{n, \text { compos }}=V_{c, \mathrm{ACI} 318}+V_{U H P C, \mathrm{ACI} 544},
$$

where $V_{c, \mathrm{ACI} 318}$ is obtained by Eqn (2) for the NSC component and $V_{U H P C, A C I 544}$ for the UHPC component is given as

$$
V_{U H P C, \mathrm{ACI} 544}=\frac{2}{3} f_{c t}\left(\frac{d}{a}\right)^{0.25} b_{w} d .
$$

In these Eqns, the tensile strength $f_{c t}$ of the UHPC was taken as $0.3\left(f_{c}^{\prime}\right)^{2 / 3}$, where $f_{c}^{\prime}[\mathrm{MPa}]$ is the compressive strength of UHPC. Additionally, the effective depth $d$ of the UHPC was assumed to be $h_{U} / 2, h_{U}$ is the thickness of UHPC, $a$ is the distance from loading point to support, and $b_{w}$ is the web width.

(b) Method B2: Based on EN 1992-1-1 (2004) and MC 2010 (2010):

$$
V_{n, \text { compos }}=V_{c, \mathrm{EC} 2}+V_{U H P C, \mathrm{MC} 2010}
$$

where $V_{c, \mathrm{EC} 2}$ is obtained by Eqn (3) for the NSC component and $V_{U H P C, M C 2010}$ for the UHPC component is given as:

$$
\begin{aligned}
& V_{U H P C, \mathrm{MC} 2010}= \\
& \left\{\frac{0.18}{\gamma_{c}} k\left[100 \rho_{s}\left(1+7.5 \frac{f_{\text {Ftuk }}}{f_{c t k}}\right) f_{c k}\right]^{\frac{1}{3}}\right\} b_{w} d .
\end{aligned}
$$

In these Eqns, the tensile strength $f_{c t k}$ of the UHPC was calculated as $0.3\left(f_{c}^{\prime}\right)^{2 / 3}$, where $f_{c}^{\prime}[\mathrm{MPa}]$ is the compressive strength of UHPC, and the effective depth of UHPC was set to $d=h_{U} / 2$, where $h_{U}$ is the thickness of the UHPC. Furthermore, $f_{\text {Ftuk }}$ is the characteristic value of the ultimate residual tensile strength for UHPC obtained from the crack opening $w_{u}(=1.5 \mathrm{~mm})$. Because the experiments on UHPC in this study were not conducted to determine the value of $f_{\text {Ftuk }}$, the $f_{\text {Ftuk }} / f_{\text {ctk }}$ ratio was taken as approximately 0.62 . This estimate was based on the work by Gowripalan and Gilbert (2000), in which the tensile strength of UHPC was related to the crack opening $w_{u}$. Additionally, $\gamma_{c}$ is the safety factor, $k$ is the size effect factor, $\rho_{s}$ is the longitudinal ratio, $b_{w}$ is the web width, and $f_{c k}[\mathrm{MPa}]$ is the characteristic compressive strength of UHPC.

(c) Method B3: Based on JSCE-2007 (2010) and JSCE (2006)

$$
V_{n, \text { compos }}=V_{c, \mathrm{JSCE}-2007}+V_{U H P C, \mathrm{JSCE}(2006)} \text {, }
$$

where $V_{c, \text { JSCE-2007 }}$ is obtained by Eqn (5) for the NSC component and $V_{U H P C, J S C E(2006)}$ for the UHPC component is computed as

$$
V_{U H P C, \operatorname{JSCE}(2006)}=V_{c}+V_{F} \text {. }
$$

Here, $V_{c}$ and $V_{F}$ are given by Eqns (12) and (13), respectively. Substituting $V_{c}$ and $V_{F}$ into Eqn (28) yields $V_{U H P C \text {,JSCE(2006) }}$ as

$$
\begin{aligned}
& V_{U H P C, \operatorname{JSCE}(2006)}= \\
& \frac{0.18 \sqrt{f_{c d}^{\prime}} b_{w} d}{\gamma_{b}}+\frac{\left(f_{v d} / \tan \beta_{u}\right) b_{w} z}{\gamma_{b}} .
\end{aligned}
$$

In these Eqns, the effective depth $d$ of the UHPC component was assumed to be $d=h_{U} / 2$. In the present study, the angle $\beta_{u}$ was taken as $45^{\circ} ; f_{v d}$ was approximated as $f_{v d}=f_{t k} / \gamma_{c}$, where $f_{t k}$ was calculated as $f_{t k}=0.3\left(f_{c d}^{\prime}\right)^{2 / 3}$ with $f_{c d}^{\prime}[\mathrm{MPa}]$ the design compressive strength; $\gamma_{b}$ is the member factor; $b_{w}$ is the web width; $z$ is the inner lever arm; and $h_{U}$ is the thickness of the UHPC component. 


\section{Prediction and verification}

\subsection{Predicted shear strength}

The shear strength was mainly evaluated on the OV series specimens because they experimentally failed in diagonal shear cracks. For the RE series specimens, which failed experimentally in flexure, the shear strengths of these specimens were additionally computed for reference.

The shear force $V_{n, \text { exp }}$ was experimentally obtained as $V_{n, \exp }=P_{u} / 2$, where $P_{u}$ is the ultimate load, and the nominal shear force $V_{n \text {,compos }}$ was predicted using the methods in Section 3. The experimental-to-predicted shear strength ratio $V_{n \text {,exp }} / V_{n \text {,compos }}$ for the OV (specimens failed in shear) and $\mathrm{RE}$ (specimens mainly failed in flexure) series were calculated and are listed in Tables 3 and 4, respectively. Tables 3 and 4 also provide the means, standard deviations (SDs), and coefficients of variation (COVs) for the $V_{n, \text { exp }} / V_{n, \text { compos }}$ ratios of each series.

The predicted shear strength for the OV series specimens, which experimentally failed in shear, shown in Table 3 agreed reasonably well with the experimental results.
From Table 3, the predictions based on the converting the volume fraction of steel fibres were found to yield a better accuracy than those obtained using the sum of the two contributions to the shear strength. The modification of ACI 318 (2008) (Method A1), EN 1992-1-1 (2004) (Method A2), and JSCE-2007 (2010) (Method A3) yielded mean $V_{n, \exp } / V_{n, \text { compos }}$ ratios of $1.20,1.16$, and 1.25 , SDs of 0.21 , 0.19 , and 0.18 , and COVs of $17.6 \%, 16.1 \%$, and $14.6 \%$, respectively. Regarding the methods adopting the sum of the two shear strength contributions, Methods B1, B2, and B3 yielded mean $V_{n \text {,exp }} / V_{n \text {,compos }}$ ratios of $1.31,1.41$, and 0.92 , SDs of $0.21,0.44$, and 0.37 , and COVs of $15.9 \%, 30.8 \%$, and $39.7 \%$, respectively. In addition to the OV series, although the RE series specimens failed experimentally in flexure, the shear strengths of these specimens were calculated and are listed in Table 4 for reference. Since the flexure failure occurred in RE series except RE-0 and RE-20, the comparison of the predicted shear strength and the experimental results showed relatively poor correlations for $\mathrm{RE}$ series. For all adopted design Eqns for the RE series, the mean $V_{n, \text { exp }} / V_{n, \text { compos }}$ ratios, SDs, and COVs ranged

Table 3. Predicted and experimental shear strength results (OV series including RE-0)

\begin{tabular}{|c|c|c|c|c|c|c|c|c|}
\hline \multirow{3}{*}{ Specimen } & \multirow{2}{*}{\multicolumn{2}{|c|}{ Experimental results }} & \multicolumn{6}{|c|}{ Predicted shear strength } \\
\hline & & & \multicolumn{6}{|c|}{$V_{n, \exp } / V_{n, \text { compos }}$} \\
\hline & $V_{n, \exp }(\mathrm{kN})$ & Failure mode & Method A1 & Method A2 & Method A3 & Method B1 & Method B2 & Method B3 \\
\hline RE-0 & 30.54 & Shear & $1.57^{\star}$ & $1.48^{\star}$ & $1.54^{\star}$ & $1.57^{\star}$ & $1.48^{\star}$ & $1.54^{\star}$ \\
\hline OV-25 & 36.78 & Shear & 1.15 & 1.13 & 1.18 & 1.33 & 1.78 & 0.86 \\
\hline OV-25a & 38.98 & Shear & 1.13 & 1.07 & 1.17 & 1.41 & 0.99 & 0.91 \\
\hline OV-50 & 38.99 & Shear & 1.02 & 1.00 & 1.06 & 1.01 & 1.88 & 0.59 \\
\hline OV-50a & 47.53 & Shear & 1.15 & 1.11 & 1.29 & 1.23 & 0.94 & 0.72 \\
\hline Mean & - & - & 1.20 & 1.16 & 1.25 & 1.31 & 1.41 & 0.92 \\
\hline SD & - & - & 0.21 & 0.19 & 0.18 & 0.21 & 0.44 & 0.37 \\
\hline $\mathrm{COV}$ & - & - & $17.6 \%$ & $16.1 \%$ & $14.6 \%$ & $15.9 \%$ & $30.8 \%$ & $39.7 \%$ \\
\hline
\end{tabular}

Note: ${ }^{*} V_{n, \text { compos }}$ is obtained from an RC design code (i.e. Eqns (2), (3) and (5)).

Table 4. Predicted and experimental shear strength results (RE series)

\begin{tabular}{|l|c|c|c|c|c|c|c|c|}
\hline \multirow{2}{*}{ Specimen } & \multicolumn{3}{|c|}{ Experimental results } & \multicolumn{6}{|c|}{ Predicted shear strength } \\
\cline { 2 - 10 } & & \multicolumn{7}{|c|}{$V_{n, \exp } / V_{n, \text { compos }}$} \\
\cline { 2 - 10 } & $V_{n, \exp }(\mathrm{kN})$ & Failure mode & Method A1 & Method A2 & Method A3 & Method B1 & Method B2 & Method B3 \\
\hline RE-0 & 30.54 & Shear & $1.57^{*}$ & $1.48^{*}$ & $1.54^{*}$ & $1.57^{*}$ & $1.48^{*}$ & $1.54^{*}$ \\
\hline RE-20 & 28.59 & Flexure-shear & 1.14 & 1.05 & 1.09 & 1.14 & 1.48 & 0.77 \\
\hline RE-32 & 21.84 & Flexure & 0.90 & 0.79 & 0.88 & 1.15 & 0.88 & 0.74 \\
\hline RE-50 & 27.69 & Flexure & 1.21 & 1.00 & 1.25 & 1.07 & 0.63 & 0.52 \\
\hline RE-100 & 56.48 & Flexure & $1.22^{* *}$ & $0.84^{* *}$ & $0.61^{* *}$ & $1.22^{* *}$ & $0.84^{* *}$ & $0.61^{* *}$ \\
\hline Mean & - & - & $\mathbf{1 . 2 1}$ & $\mathbf{1 . 0 3}$ & $\mathbf{1 . 0 7}$ & $\mathbf{1 . 2 3}$ & $\mathbf{1 . 0 6}$ & $\mathbf{0 . 8 4}$ \\
\hline SD & - & - & $\mathbf{0 . 2 4}$ & $\mathbf{0 . 2 7}$ & $\mathbf{0 . 3 5}$ & $\mathbf{0 . 2 0}$ & $\mathbf{0 . 3 9}$ & $\mathbf{0 . 4 0}$ \\
\hline COV & - & - & $\mathbf{1 9 . 9 \%}$ & $\mathbf{2 6 . 4 \%}$ & $\mathbf{3 3 . 0 \%}$ & $\mathbf{1 6 . 1 \%}$ & $\mathbf{3 7 . 0 \%}$ & $\mathbf{4 8 . 6 \%}$ \\
\hline
\end{tabular}

Note: ${ }^{\star} V_{n, \text { compos }}$ is obtained from an RC design code (i.e. Eqns (2), (3), and (5)).

${ }^{* *} V_{n, \text { compos }}$ is obtained from an FRC design code (i.e. Eqns (6), (8), and (11)). 
from 0.84 to 1.23 , from 0.20 to 0.40 , and from $16.1 \%$ to $48.6 \%$, respectively.

The shear forces of the OV series specimens are plotted in Figure 4. As shown in these plots, all design Eqns except Method B3 (Figure 4(f)) yielded estimates safely below the target line or approximately agreed with the target line representing $V_{n \text {,exp }}=V_{n \text {,compos }}$. To further compare the predicted and experimental shear forces of each of the OV series specimens, the results were plotted in a bar chart, as shown in Figure 5. From Figure 5, all adopted design

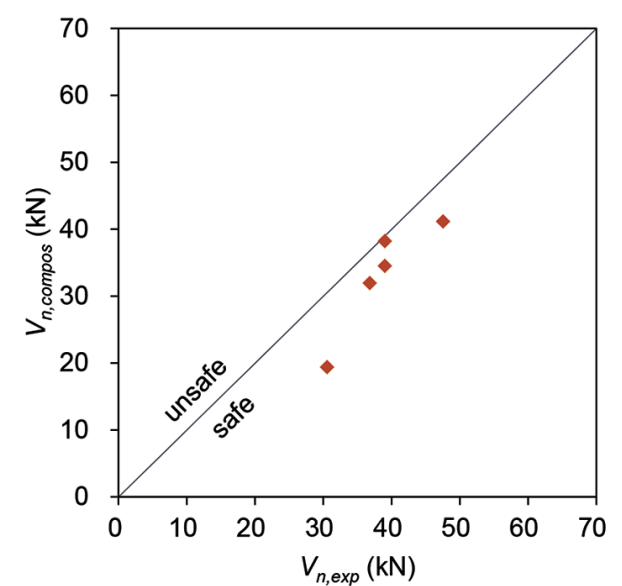

(a) Method A1

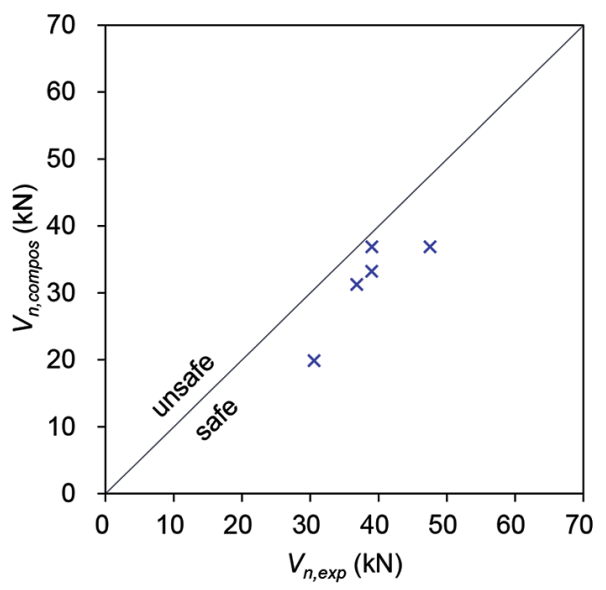

(c) Method A3

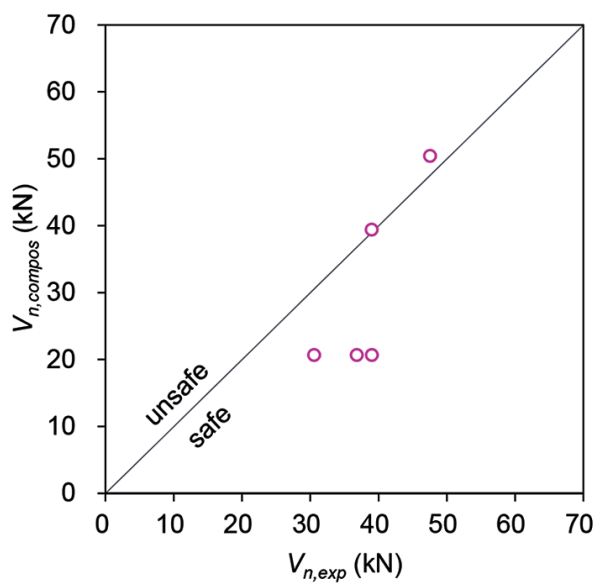

(e) Method B2 codes showed promising results. It is of interest that the Eqns for Methods B1 and B3 do not include a term for the ratio of the longitudinal rebar. The predicted shear strengths were the same at the same UHPC thickness, as can be seen by comparing the OV-25 and OV-25a results and the OV-50 and OV-50a results. For Method B2, the prediction greatly underestimated the actual strengths in the cases of OV-25 and OV-50 because no steel rebar was present in the UHPC (i.e. the UHPC shear contribution was zero in Eqn (26)).

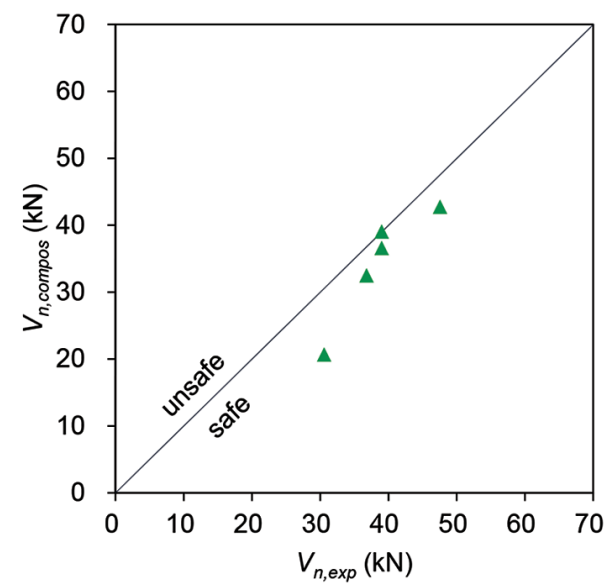

(b) Method A2

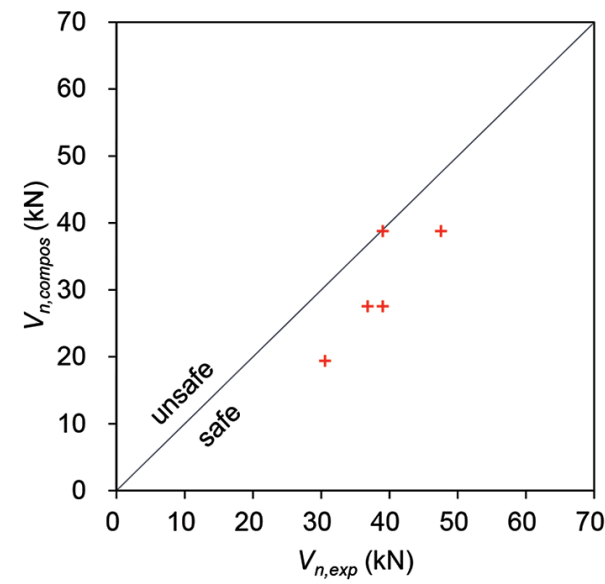

(d) Method B1

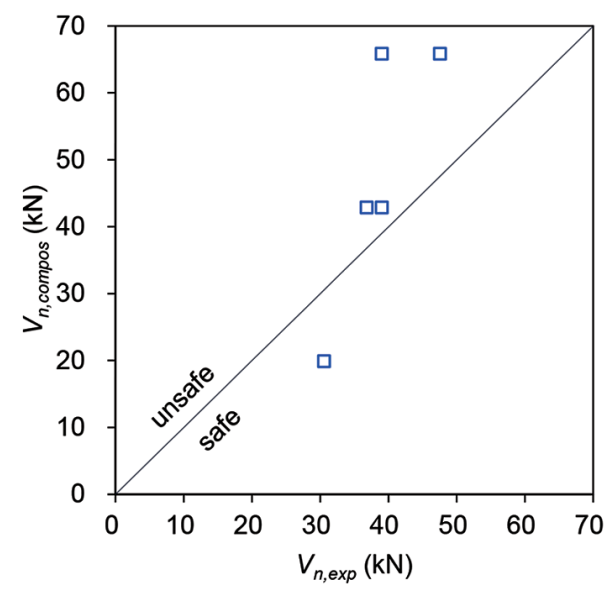

(f) Method B3

Figure 4. Predicted shear forces plotted against experimental results for OV series specimens (including RE-0) 


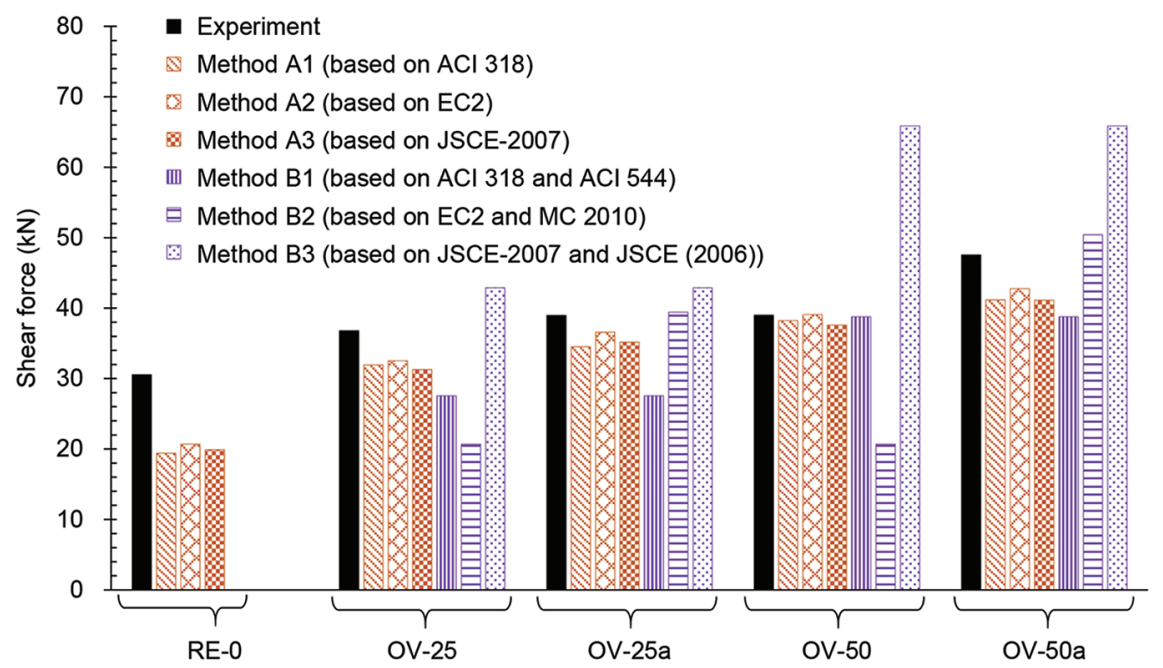

Figure 5. Shear capacities for OV series specimens (including RE-0)

\subsection{Prediction of failure mode}

In the present study, failure mode prediction was conducted using the shear force $V_{\text {fle }}$ given by the flexural moment $M_{f l e}$ computed using the method reported by Shirai et al. (2018). This shear force $V_{f l e}$ was compared with those $V_{n, \text { compos }}$ obtained using the six methods adopted in the shear strength prediction (Section 4.1). The calculation method and the flexural moment $M_{f l e}$ results are summarised as follows.

In accordance with the method by Shirai et al. (2018), the flexural moment of the UHPC-concrete members was computed based on the equilibrium with geometrical compatibility in a section of the members. A representation of the assumed stresses and strains in the UHPC-concrete section is shown in Figure 6.

From Figure 6, the equilibrium equation is expressed as:

$$
C_{c}+C_{s c}=T_{s t}+T_{U H P C},
$$

where:

$$
\begin{aligned}
& C_{c}=0.85 f_{c}^{\prime} \alpha x_{n} b_{w} ; \\
& C_{s c}=A_{s}^{\prime} \sigma_{s}^{\prime} ; \\
& T_{s t}=A_{s U} \sigma_{s U} ; \\
& T_{U H P C}=A_{U H P C} \sigma_{t} .
\end{aligned}
$$

The flexural moment capacity $M_{f l e}$ is then given by:

$$
\begin{aligned}
M_{f l e}= & A_{s} \sigma_{s}\left(d-\frac{\alpha x_{n}}{2}\right)+A_{U H P C} \sigma_{t}\left(d_{U}-\frac{\alpha x_{n}}{2}\right)+ \\
& A_{s}^{\prime} \sigma_{s}^{\prime}\left(\frac{\alpha x_{n}}{2}-d^{\prime}\right),
\end{aligned}
$$

where:

$b_{w}=$ width of the specimen.

$d^{\prime}=$ distance from the top of the concrete surface to the radial centre of the top rebar.

$d$ = assumed effective depth (Figure 6).

$d_{U}=$ distance from the top of the concrete surface to the centre of the UHPC layer $\left(d_{U}=h_{C}+h_{U} / 2\right)$.

$h_{C}=$ height of RC member.

$h_{U}=$ thickness of UHPC.

$x_{n}=$ distance between the top surface and neutral axis (Figure 6). $x_{n}$ can be obtained using the strain compatibility and equilibrium condition and checking the strain level in the reinforcement rebar.

$f_{c}^{\prime}=$ compressive strength of concrete.

$\alpha=$ factor relating the depth of equivalent rectangular compressive stress block to neutral axis depth and it shall be taken as 0.85 in the present study (ACI 318 2008).

$A_{s}^{\prime}=$ area of top rebar.

$A_{s}=$ area of bottom rebar.

$A_{s U}=$ area of longitudinal rebar in UHPC.

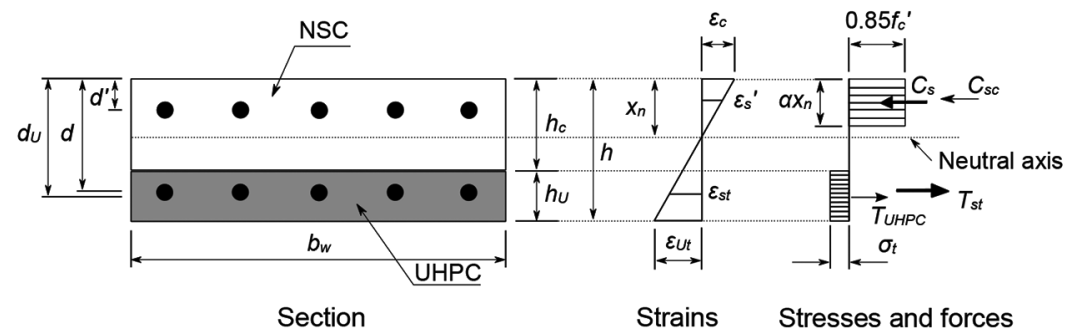

Figure 6. Calculation assumptions for the flexural strength of the UHPC-concrete members (Shirai et al. 2018) 
Table 5. Predicted failure modes for RE series specimens based on the previously computed flexural moment

\begin{tabular}{|c|c|c|c|c|c|c|c|c|c|c|}
\hline \multirow{3}{*}{ Specimen } & \multirow{2}{*}{\multicolumn{2}{|c|}{ Experimental results }} & \multirow{2}{*}{\multicolumn{2}{|c|}{$\begin{array}{l}\text { Predicted flexural } \\
\text { strength }\end{array}$}} & \multicolumn{6}{|c|}{ Predicted shear strength and failure mode } \\
\hline & & & & & \multicolumn{6}{|c|}{$\begin{array}{c}V_{n, \text { compos }} / V_{\text {fle }} \\
\text { (Predicted failure mode) }\end{array}$} \\
\hline & $M_{u, \exp }(\mathrm{kNm})$ & $\begin{array}{l}\text { Failure } \\
\text { mode }\end{array}$ & $M_{u, \exp } / M_{f l e}$ & $V_{f l e}(\mathrm{kN})$ & $\begin{array}{c}\text { Method } \\
\text { A1 }\end{array}$ & $\begin{array}{l}\text { Method } \\
\text { A2 }\end{array}$ & $\begin{array}{l}\text { Method } \\
\text { A3 }\end{array}$ & $\begin{array}{l}\text { Method } \\
\text { B1 }\end{array}$ & $\begin{array}{l}\text { Method } \\
\text { B2 }\end{array}$ & $\begin{array}{l}\text { Method } \\
\text { B3 }\end{array}$ \\
\hline $\mathrm{RE}-0$ & 18.32 & Shear & 1.18 & 25.85 & $\begin{array}{c}0.75 \\
\text { (Shear) }\end{array}$ & $\begin{array}{c}0.80 \\
\text { (Shear) }\end{array}$ & $\begin{array}{c}0.77 \\
\text { (Shear) }\end{array}$ & $\begin{array}{c}0.75 \\
\text { (Shear) }\end{array}$ & $\begin{array}{c}0.80 \\
\text { (Shear) }\end{array}$ & $\begin{array}{c}0.77 \\
\text { (Shear) }\end{array}$ \\
\hline RE-20 & 17.15 & $\begin{array}{l}\text { Flexure- } \\
\text { shear }\end{array}$ & 1.07 & 26.78 & $\begin{array}{c}0.94 \\
\text { (Shear) }\end{array}$ & $\begin{array}{c}1.02 \\
\text { (Flexure) }\end{array}$ & $\begin{array}{c}0.98 \\
\text { (Shear) }\end{array}$ & $\begin{array}{c}0.94 \\
\text { (Shear) }\end{array}$ & $\begin{array}{c}0.72 \\
\text { (Shear) } \\
\end{array}$ & $\begin{array}{c}1.39 \\
\text { (Flexure) }\end{array}$ \\
\hline RE-32 & 13.10 & Flexure & 0.80 & 27.19 & $\begin{array}{c}0.89 \\
\text { (Shear) }\end{array}$ & $\begin{array}{c}1.02 \\
\text { (Flexure) }\end{array}$ & $\begin{array}{c}0.91 \\
\text { (Shear) }\end{array}$ & $\begin{array}{c}0.70 \\
\text { (Shear) }\end{array}$ & $\begin{array}{c}0.91 \\
\text { (Shear) }\end{array}$ & $\begin{array}{c}1.09 \\
\text { (Flexure) }\end{array}$ \\
\hline RE-50 & 16.61 & Flexure & 1.00 & 27.59 & $\begin{array}{c}0.83 \\
\text { (Shear) }\end{array}$ & $\begin{array}{c}1.00 \\
\text { (Flexure) }\end{array}$ & $\begin{array}{c}0.80 \\
\text { (Shear) }\end{array}$ & $\begin{array}{c}0.94 \\
\text { (Shear) }\end{array}$ & $\begin{array}{c}1.59 \\
\text { (Flexure) }\end{array}$ & $\begin{array}{c}1.93 \\
\text { (Flexure) }\end{array}$ \\
\hline RE-100 & 33.88 & Flexure & 0.99 & 56.91 & $\begin{array}{c}0.81 \\
\text { (Shear) }\end{array}$ & $\begin{array}{c}1.18 \\
\text { (Flexure) }\end{array}$ & $\begin{array}{c}1.63 \\
\text { (Flexure) }\end{array}$ & $\begin{array}{c}0.81 \\
\text { (Shear) }\end{array}$ & $\begin{array}{c}1.18 \\
\text { (Flexure) }\end{array}$ & $\begin{array}{c}1.63 \\
\text { (Flexure) }\end{array}$ \\
\hline Mean & - & - & 1.01 & - & - & - & - & - & - & - \\
\hline SD & - & - & 0.14 & - & - & - & - & - & - & - \\
\hline $\mathrm{COV}$ & - & - & $13.6 \%$ & - & - & - & - & - & - & - \\
\hline
\end{tabular}

Note: $V_{f l e}=$ shear force obtained at the calculated flexural moment $M_{f l e}$.

$A_{U H P C}=$ area of UHPC $\left(A_{U H P C}=b_{w} h_{U}\right)$.

$\sigma_{s}^{\prime}=$ stress of top rebar.

$\sigma_{s}=$ stress of bottom rebar.

$\sigma_{s U}=$ stress of longitudinal rebar in UHPC.

$\sigma_{t}=$ tensile stress of UHPC obtained by adopting the formulation provided by ACI 544 (1988) as:

$$
\sigma_{t}=0.00772(l / d) \rho_{f} F_{b e},
$$

where $l$ is the fibre length, $d$ is the effective depth, $\rho_{f}$ is the volume fraction of steel fibres, and $F_{b e}$ is a factor describing the bond efficiency of the fibres. More details can be found in ACI 544 (1988).

The experimental-to-predicted moment capacity ratios $M_{u, e x p} / M_{f l e}$ for specimen RE series are listed in Table 5. For the ratios reported in Table 5, $M_{u, \exp }$ is the ultimate moment experimentally obtained as $M_{u, \exp }=V_{n, \exp } a$, where $a$ is the distance from the loading point to the support. As shown in Table 5, the predicted and experimental flexural moments for the RE series showed good agreement with a mean $M_{u, \text { exp }} / M_{\text {fle }}$ ratio of 1.01 , an SD of 0.14 , and a COV of 13.6\% (Shirai et al. 2018).

In the present study, the expected failure mode was evaluated from the ratio $V_{n \text {,compos }} / V_{\text {fle }}$. When $V_{n \text {,compos }} /$ $V_{f l e}<1$, the failure mode was expected to be shear failure, and flexure failure was expected otherwise. As shown in Table 5, although the predicted failure modes did not agree with the experimental modes in all calculation cases, it may be worthwhile to consider these predicted failure modes. Among the considered prediction methods, the most accurate were Methods A2 (based on EC2) and B3 (based on JSCE-2007 (2010) and JSCE (2006)).

\section{Conclusions}

A total of six methods of predicting the shear capacity of UHPC-concrete composite members based on existing design codes were presented in this paper. The predicted shear strength of RC slabs strengthened with various UHPC configurations in the tensile zone were verified against experimental results. From the assessments conducted in this study, the following conclusions were reached.

1. The shear strength of UHPC-concrete members obtained using the methods based on converting the volume fraction of steel fibres generally provided better prediction results than the methods adopting the sum of the two shear strength contributions $V_{c}$ and $V_{U H P C}$.

2. The methods based on converting the volume fraction of steel fibres, Methods A1, A2, and A3, yielded predicted shear strengths for the OV series specimens with mean $V_{n, \exp } / V_{n, \text { compos }}$ ratios of $1.20,1.16$, and 1.25 , SDs of $0.21,0.19$, and 0.18 , and COVs of $17.6 \%, 16.1 \%$, and $14.6 \%$, respectively. The methods summing the two components, Methods B1, B2, and B3, yielded mean $V_{n, \text { exp }} / V_{n, \text { compos }}$ ratios of $1.31,1.41$, and 0.92 , SDs of $0.21,0.44$, and 0.37 , and COVs of $15.9 \%, 30.8 \%$, and $39.7 \%$, respectively.

3. The failure modes determined from the predicted shear force obtained at the predicted flexural moment and those obtained using the adopted methods for the shear force prediction were compared. The failure modes predicted using Methods A2 and B3 were found to be the most accurate among the six methods. 
4. From the present study, the proposed methods for UHPC-concrete members based on modifications to existing design models yielded promising results with reasonable accuracy. However, a more realistic and accurate model for UHPC-concrete members is needed in future work. In addition, the test data used to validate the proposed methods of shear strength prediction were limited to nine slab specimens, which consisted of five slabs experimentally failed in shear and other four slabs experimentally failed in flexure.

\section{Acknowledgements}

The authors gratefully acknowledge the financial support from the Toda Scholarship Foundation 2017 Research Grant for this work.

\section{Disclosure statement}

The present authors have no conflict of interests.

\section{References}

ACI 318. 2008. Building code requirements for structural concrete (ACI 318) and commentary. American Concrete Institute.

ACI Committee 544 (ACI 544). 1988. Design considerations for steel fiber reinforced concrete, ACI Structural Journal 85(5): 563-579.

Alaee, F. J.; Karihaloo, B. L. 2003. Retrofitting of reinforced concrete beams with CARDIFRC, Journal of Composites for Construction 7: 174-186. https://doi.org/10.1061/(ASCE)1090-0268(2003)7:3(174)

Brühwiler, E.; Denarie, E. 2008. Rehabilitation of concrete structures using ultra-high performance fibre reinforced concrete, in Proceedings of the UHPC-2008: The Second International Symposium on Ultra High Performance Concrete, 05-07.

CEB-FIB Model Code (MC 2010). 2010. The first draft of the fib Model Code for Concrete Structures. International Federation for Structural Concrete (fib).

EN 1992-1-1 Design of concrete structures: Part 1-1: General rules and rules for buildings. British Standards Institution. 2004.

Gowripalan, N.; Gilbert, R. 2000. Design guidelines for ductal prestressed concrete beams. Design guide. University of New South Wales, Sydney, Australia [online], [cited 05 September 2018]. Available from Internet: http://docshare04.docshare.tips/files/20028/200286367.pdf

Graybeal, B. A. 2005. Characterization of the behavior of ultrahigh performance concrete: $\mathrm{PhD}$ thesis. University of Maryland, USA.

Graybeal, B. A.; Baby, F. 2013. Development of direct tension test method for ultra-high-performance fiber-reinforced concrete, ACI Materials Journal 110(2): 177-186.

Habel, K. 2004. Structural behaviour of elements combining ultrahigh performance fibre reinforced concretes (UHPFRC) and reinforced concrete: $\mathrm{PhD}$ thesis. École Polytechnique Fédérale de Lausanne (EPFL), Switzerland.

Habel, K.; Denarié, E.; Brühwiler, E. 2007. Experimental investigation of composite ultra-high-performance fiber-reinforced concrete and conventional concrete members, ACI Structural Journal 104(1): 93-101.
JSCE Concrete Committee. 2006. Recommendation for design and construction of ultra high strength fiber reinforced concrete structures (Draft). Guidelines for Concrete, No. 9. Japan Society of Civil Engineers (JSCE).

JSCE-2007. 2010. Standard specifications for concrete structures 2007 "Design". Guidelines for Concrete, No. 15. Japan Society of Civil Engineers (JSCE).

Kani, G. N. J. 1964. The riddle of shear failure and its solution, ACI Journal, Proceedings 61(4): 441-468.

Kotsovos, M. D. 1983. Mechanisms of 'shear' failure, Magazine of Concrete Research 35(123): 99-106. https://doi.org/10.1680/macr.1983.35.123.99

Noshiravani, T.; Brühwiler, E. 2013a. Analytical model for predicting response and flexure-shear resistance of composite beams combining reinforced ultrahigh performance fiberreinforced concrete and reinforced concrete, Journal of Structural Engineering 140(6). https://doi.org/10.1061/(ASCE)ST.1943-541X.0000902

Noshiravani, T.; Brühwiler, E. 2013b. Experimental investigation on reinforced ultra-high-performance fiber-reinforced concrete composite beams subjected to combined bending and shear, ACI Structural Journal 110(2): 251-261.

Oesterlee, C. 2010. Structural response of reinforced UHPFRC and $R C$ composite members: $\mathrm{PhD}$ thesis. École Polytechnique Fédérale de Lausanne (EPFL), Switzerland. https://infoscience.epfl.ch/record/169623?ln=en

Shirai, K.; Yin, H.; Teo, W. 2018. Flexural strength calculation of the RC members rehabilitated with UHPC, in Proceedings of the Japan Concrete Institute 40: 1237-1242.

Wille, K.; El-Tawil, S.; Naaman, A. 2014. Properties of strain hardening ultra high performance fiber reinforced concrete (UHP-FRC) under direct tensile loading, Cement and Concrete Composites 48: 53-66. https://doi.org/10.1016/j.cemconcomp.2013.12.015

Yin, H.; Shirai, K.; Teo, W. 2018. Shear capacity prediction of reinforced concrete members strengthened with ultra-high performance concrete overlay, in Proceedings of the Japan Concrete Institute 40: 1243-1248.

Yin, H.; Teo, W.; Shirai, K. 2017. Experimental investigation on the behaviour of reinforced concrete slabs strengthened with ultra-high performance concrete, Construction and Building Materials 155: 463-474.

https://doi.org/10.1016/j.conbuildmat.2017.08.077

Yoo, D. Y.; Banthia, N. 2016. Mechanical properties of ultrahigh-performance fiber-reinforced concrete: A review, Cement and Concrete Composites 73: 267-280. https://doi.org/10.1016/j.cemconcomp.2016.08.001

Yoo, D. Y.; Yoon, Y. S. 2016. A review on structural behavior, design, and application of ultra-high-performance fiber-reinforced concrete, International Journal of Concrete Structures and Materials 10(2): 125-142. https://doi.org/10.1007/s40069-016-0143-x 